\title{
Transcriptome-wide Association Study of Circulating IgE Levels Identifies Novel Targets for Asthma and Allergic Diseases
}

\author{
Recto Kathryn ${ }^{1,2}$, Huan Tianxiao ${ }^{1,2}$, Lee Dong Heon ${ }^{1,2}$, Lee Gha Young ${ }^{1,2}$, Gereige Jessica ${ }^{3}$, Yao Chen ${ }^{1,2}$, Hwang Shih-Jen ${ }^{1,2}$, \\ Joehanes Roby ${ }^{1,2}$, Kelly Rachel S ${ }^{4}$, Lasky-Su Jessica ${ }^{4}$, O’Connor George ${ }^{3}$, Levy Daniel ${ }^{1,2}$. \\ ${ }^{1}$ The Population Sciences Branch, National Heart, Lung, and Blood Institute, National Institutes of Health, Bethesda, MD 20892 , \\ USA. \\ ${ }^{2}$ The Framingham Heart Study, Framingham, MA 01702, USA. \\ ${ }^{3}$ Boston University School of Medicine, Pulmonary Center, Boston, MA 02118, USA. \\ ${ }^{4}$ Brigham and Women's Hospital, Channing Division of Network Medicine, Boston, MA 02115, USA.
}

\begin{abstract}
Measurement of circulating immunoglobulin E ( $\operatorname{IgE}$ ) concentration is helpful for diagnosing and treating asthma and allergic diseases. Identifying gene expression signatures associated with IgE might elucidate novel pathways for IgE regulation. To this end, we performed a discovery transcriptome-wide association study (TWAS) to identify differentially expressed genes associated with circulating IgE levels in wholeblood derived RNA from 5,345 participants in the Framingham Heart Study (FHS) across 17,873 mRNA gene-level transcripts. We identified 216 significant transcripts at a false discovery rate (FDR $<0.05$. We conducted replication using the meta-analysis of two independent external studies: the Childhood Asthma Management Program ( $n=610)$ and the Genetic Epidemiology of Asthma in Costa Rica Study $(n=326)$; we then reversed the discovery and replication cohorts, which revealed 59 significant genes that bidirectionally replicated. Gene ontology analysis revealed that many of these genes were implicated in immune function pathways, including defense response, inflammatory response, and cytokine production. Mendelian randomization (MR) analysis revealed four genes (CLC, CCDC21, S100A13, and GCNT1) as putatively causal $(\mathrm{p}<0.05)$ regulators of IgE levels. GCNT1 (beta $=1.5, \mathrm{p}=0.01$ ) - which is a top result in the MR analysis of expression in relation to asthma and allergic diseases-plays a role in regulating $\mathrm{T}$ helper type 1 (Th1) cell homing, lymphocyte trafficking, and B cell differentiation. Our findings build upon prior knowledge of $\mathrm{IgE}$ regulation and provide a deeper understanding of underlying molecular mechanisms. The IgE-associated genes that we identified-particularly those implicated in MR analysis — can be explored as promising therapeutic targets for asthma and IgE-related diseases.
\end{abstract}

\section{Introduction}

Immunoglobulin $\mathrm{E}$ (IgE) is an antibody produced by B cells located in lymph nodes in response to antigenic stimuli and its production requires T helper type $2(\mathrm{Th} 2)$ cells ${ }^{1}$. Once released into the circulation, IgE contributes to immunity to respiratory viruses and parasites and protects against venom toxin exposure ${ }^{2,3}$. IgE also plays a role in disease processes related to allergic asthma, allergic rhinitis, atopic dermatitis, and food allergies ${ }^{4}$. According to recent estimates from the World Health Organization, asthma affected 300 million people worldwide in 2012 and this number is projected to increase to 400 million by $2025^{4}$. Given the widespread burden of IgE-mediated allergic diseases, investigating the maladaptive role of IgE in immune responses may highlight promising therapies for asthma and related conditions.

Genome-wide association studies (GWAS) have identified single nucleotide polymorphisms (SNPs) at the STAT6, FCERIA, IL13, IL4/RAD50, and the major histocompatibility complex (MHC) loci that are associated with circulating $\operatorname{IgE}$ concentrations ${ }^{5-8}$. Investigating the transcriptomic signature of $\operatorname{IgE}$ concentration may shed light on molecular regulatory mechanisms ${ }^{9-11}$. Virkud et al. examined gene expression networks in whole-blood in two differing asthma populations and identified 31 transcripts associated with serum total IgE that replicated across study cohorts ${ }^{12}$. To date, however, there have been 
medRxiv preprint doi: https://doi.org/10.1101/2020.08.17.20176479; this version posted August 18, 2020. The copyright holder for this preprint (which was not certified by peer review) is the author/funder, who has granted medRxiv a license to display the preprint in perpetuity. All rights reserved. No reuse allowed without permission.

no published large-scale transcriptome-wide association studies (TWAS) of circulating IgE concentration. While most of the current literature has focused on certain aspects of IgE-related gene regulatory networks, our study was designed to provide a more comprehensive framework for understanding the molecular regulation of IgE by integrating TWAS of IgE with GWAS of IgE and IgE-related diseases.

In this study, we hypothesized a priori that IgE-associated transcriptomic changes impact IgE regulation, which in turn play a role in the pathology of IgE-related diseases, such as asthma and allergic diseases. First, we performed a discovery TWAS of IgE in 5345 Framingham Heart Study (FHS) participants. To validate our results, we conducted replication based on the meta-analysis of two independent external studies: the Childhood Asthma Management Program (CAMP) and the Genetic Epidemiology of Asthma in Costa Rica Study (GACRS). We then reversed the discovery and replication sets. Second, we conducted Mendelian randomization (MR) to determine the direction of effect and infer causal relations between gene expression and circulating IgE levels. Two-sample MR analyses were then used to infer causal relations between IgE-related gene expression and IgE-related diseases, including asthma and allergy, by linking genetic variants associated with gene expression (i.e. cis-eQTLs) with GWAS of asthma and allergy, respectively ${ }^{13}$. By exploring the multidimensional interrelations of gene expression and circulating IgE levels, we provide a deeper understanding of the molecular pathways underlying $\operatorname{IgE}$ regulation and highlight promising therapeutic targets for IgE-related diseases.

\section{Methods}

\section{Discovery in the FHS}

Study population: A flowchart of the study design is displayed in Figure 1. The FHS is a communitybased study ${ }^{14}$. The study sample consisted of 5345 individuals from the FHS Offspring $(n=2251)$ and Third Generation ( $n=3094$ ) cohorts, in whom IgE levels and gene expression were measured. The study protocol was approved by the Institutional Review Board at Boston University Medical Center (Boston, MA). All participants gave informed consent for genetic research.

Assessment of IgE levels: Serum total IgE concentration was measured on FHS Offspring (Exam 7: 19982001) and Third Generation (Exam 1: 2002-2005) cohort participants. Total IgE measurements were performed using the Phadia Immunocap 100 system, in which an anti-IgE antibody is bound to a solidphase carrier followed by fluoroenzyme-based quantitative measurement of total IgE with high precision and reproducibility ${ }^{15}$.

mRNA expression data: Gene expression was measured on FHS Offspring (Exam 8: 2005-2008) and Third Generation (Exam 2: 2008-2011) cohort participants. Whole blood samples (2.5 ml) were collected in PAXgene ${ }^{\mathrm{TM}}$ tubes (PreAnalytiX, Hombrechtikon, Switzerland). mRNA expression was profiled using the Affymetrix Human Exon 1.0 ST GeneChip (Santa Clara, CA) platform that includes 18,000 genelevel transcripts. The data normalization was described previously ${ }^{16}$.

Association of gene expression with IgE levels: A linear mixed model implemented in the lmekin() package in $R$ was used to analyze associations between gene expression (RMA value) and serum total IgE concentration after adjusting for age, sex, smoking status (current, former, and never smokers), packyears, technical covariates including batch effects ${ }^{16}$, predicted blood cell fraction (including white blood cells, red blood cells, platelets, lymphocytes, monocytes, and basophils), and family structure. We performed a secondary analysis further adjusting for eosinophils.

GWAS of IgE: There have been no large-scale GWAS of serum IgE concentration published in the past five years. Given the limited availability of up-to-date IgE GWAS, we updated a previous FHS GWAS of IgE concentration ${ }^{8}$ using 1000 Genomes imputation. We characterized statistical associations between 
genome-wide polymorphisms and variation of serum $\operatorname{IgE}$ concentration using a linear mixed regression model. The updated GWAS included 7252 FHS participants from three cohorts: the FHS Original cohort (Exam 24; 1995-1998; n=495), Offspring cohort (Exam 7; 1998-2001; $n=3003$ ), and Third Generation cohort (Exam 1; 2002-2005; n=3764). DNA samples of the FHS participants who gave consent for genomic studies were genotyped using the Affymetrix 550K array (Santa Clara, CA). We applied quality control criteria of $\geq 95 \%$ call rate, $\geq 1 \times 10^{-6}$ p-value of Hardy-Weinberg equilibrium, and $\geq 1 \%$ minorallele-frequency. After applying the quality-control approved genotyping, we generated imputed wholegenome polymorphism panels using the MACH platform and applied the 1000 Genomes phase 1 platform as the reference library. For the current association analysis, we tested for statistical association assuming additive influence of polymorphisms, and required an imputation quality of $20 \%$ or higher.

Mendelian randomization analysis: We used a two-stage least squares (2SLS) Mendelian randomization (MR) method to estimate the causal relationships between gene expression and IgE measured in 5345 FHS participants. Bi-directional MR analyses were performed to test if expression drives IgE concentration (i.e., mRNA $\rightarrow$ IgE), using the top cis-eQTL for each mRNA as an instrumental variable $(\mathrm{IV})^{17}$, or if IgE concentration drives mRNA expression, using the genetic risk score combined by the top six loci from previous IgE GWAS results at $\mathrm{P}<5 \times 10^{-8}$ (i.e., IgE $\rightarrow$ mRNA) ${ }^{5,8}$. The six IgE-associated SNPs that were used in the polygenic risk score include rs2251746 (FCER1A), rs1059513 (STAT6), rs1295686 (IL13), rs2523809 (HLA-G), rs2517754 (HLA-A), and rs2858331 (HLA-DQA2) ${ }^{5,8}$. To determine the strength of the genetic instrument, an F-statistic in a linear regression model was derived from the proportion of variation in the exposure that was explained by the corresponding IV. cis-eQTLs with an F-statistic less than 10, indicating a weak instrument, were excluded. We considered an mRNA putatively causal for $\operatorname{IgE}$ (i.e., mRNA $\rightarrow \operatorname{IgE}$ ) when the MR test for mRNA $\rightarrow \operatorname{IgE}$ was significant

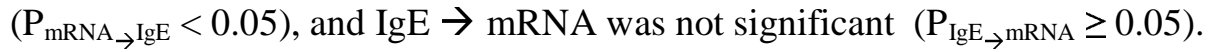

Two-sample MR was used to identify putatively causal mRNAs for both asthma and allergic diseases using the MRbase package in R. Estimated associations and effect sizes between SNPs and asthma and allergic diseases were based on UK Biobank GWAS of asthma and allergic diseases (hay fever, allergic rhinitis, or eczema) phenotypes, respectively ${ }^{13}$. Using cis-eQTLs associated with gene transcripts associated with circulating IgE levels as instrumental variables, MR analyses were used to test if gene expression drives asthma/allergy (i.e., mRNA $\rightarrow$ asthma/allergy).

Pathway analysis: Pathway analysis using Gene Ontology (GO) terms was conducted using the online Gene Set Enrichment Analysis tool (https://www.gsea-msigdb.org/gsea/msigdb/annotate.jsp), which determines whether an a priori defined gene set shows statistically significant, concordant differences between two biological states. Using an FDR q-value $<0.05$, we identified key biological pathways among the bi-directionally replicated genes associated with serum IgE concentration.

\section{Replication}

Study populations: Details of the replication studies (the Childhood Asthma Management Program $(\mathrm{CAMP})^{18-20}$ and the Genetic Epidemiology of Asthma in Costa Rica Study (GACRS) $)^{21}$ have been described previously, including the assessment of IgE levels and gene expression profiling ${ }^{20,22}$. CAMP samples are from post-trial long-term follow-up blood draws. Written parental consent and child's assent were obtained, and the study protocol was approved by the Institutional Review Boards at Hospital Nacional de Ninos (San Jose, Costa Rica) and Brigham and Women's Hospital (Boston, MA).

Statistical analysis: In both CAMP and GACRS, independent generalized linear regression models were run to test the association between each gene probe and $\log _{10}$ transformed $\operatorname{IgE}$ concentration as a 
continuous variable, using the "glmwrapper" function from the iCheck package with adjustment for age, sex, and the first two principal components. The Benjamini-Hochberg method was specified to control the false discovery rate with the q-value set to 0.05 . The final dataset in GACRS included 25060 gene probes that passed QC from 326 subjects with available data and suitable samples; in CAMP 24972 gene probes from 610 participants were available. All probes measured in CAMP were also measured in GACRS.

Meta-analysis: The results from CAMP and GACRS were meta-analyzed using the inverse normal method to combine $\mathrm{p}$-values from the R package metaRNASeq ${ }^{23}$. Analyses were weighted according to the study size.

\section{Results}

\section{FHS discovery TWAS of IgE levels}

Clinical characteristics of FHS participants (mean age $=55$ years; $54 \%$ women) and the replication cohorts (mean age $=20$ and 9 years; $37 \%$ and $43 \%$ women in CAMP and GACRS, respectively) are presented in Supplementary Table 1. In FHS participants, among 17,873 mRNA gene-level transcripts that were available for analysis, 216 were associated with total IgE concentration at FDR $<0.05$ (Supplementary Table 2) and 91 were significant at Bonferroni-corrected $p$-value threshold of $p<2.80 \times 10^{-6}(0.05 / 17,873)$. The top thirty genes associated with serum IgE concentration are presented in Table 1 . A volcano plot shows that the vast majority of genes at FDR $<0.05$ (87.5\% or 189/216) had expression levels that were positively associated with IgE (Figure 4).

After adjusting for eosinophil count (Supplementary Table 3), fewer significant genes were identified (12 genes at FDR $<0.05$, and six at Bonferroni-corrected $\left.\mathrm{p}<2.80 \times 10^{-6}\right)$. The attenuation of association is because eosinophil count was correlated with $\operatorname{IgE}$ level $\left(\mathrm{R}=0.24, \mathrm{p}<1 \times 10^{-16}\right)$. There was concordance of effect estimates (betas) for the IgE-gene expression results with versus without adjustment for eosinophils $\left(\mathrm{R}=0.46, \mathrm{p}<1 \times 10^{-16}\right.$; Supplementary Figure 1).

\section{Bi-directional Replication}

Out of 216 unique transcripts at FDR $<0.05$ from discovery in FHS, 59 unique transcripts replicated in the meta-analyzed results from GACRS and CAMP (Supplementary Table 4). We defined replication as genes at p-value $<2.44 \times 10^{-4}(0.05 / 205)$, as only 205 of the 216 significant genes in FHS were available for analysis in the replication cohorts. Forest plots of the top ten genes in this replicated gene set are provided in Supplementary Figure 2.

We performed reverse replication with the meta-analysis of GACRS/CAMP as the discovery set and FHS as the replication set. From the meta-analysis of GACRS/CAMP, we identified 135 unique transcripts associated with total IgE levels at FDR $<0.05$. Among these, 114 transcripts mapping to 112 unique genes were available in FHS (TRERF1 and ACOT11 were each linked to two separate transcripts). We defined replication as $\mathrm{p}<4.39 \times 10^{-4}(0.05 / 114)$; all 114 significant transcripts from discovery in GACRS/CAMP replicated in FHS (Supplementary Table 5). Furthermore, all 59 genes that replicated in GACRS/CAMP based on FHS discovery were within the 114 replicated gene set using GACRS/CAMP as discovery-i.e. 59 genes demonstrated bi-directional replication, demonstrating the robustness of association signals.

\section{Gene Ontology}

Using the 216 FDR-signficant genes from FHS discovery, we conducted gene ontology to identify key biological pathways among the top genes differentially expressed in relation to total IgE levels (Table 2). 
Multiple genes from this gene set were associated with pathways involved in inflammation and other immune system responses.

Secondary gene ontology analysis was performed on the 59 genes that bi-directionally replicated between FHS and GACRS/CAMP. Similar to the larger FHS discovery gene set, multiple genes from the bidirectionally replicated gene set were implicated in pathways related to the immune response (Supplementary Table 6).

\section{Mendelian Randomization for total IgE levels}

A Manhattan plot and a Q-Q plot (lambda 1.017) displaying the updated FHS IgE GWAS results are provided in Figures 2 and 3, respectively. A list of significant SNPs $\left(p<5 \times 10^{-8}\right)$ from the updated $\operatorname{IgE}$ GWAS is reported in Supplementary Table 7. Among the 216 FDR-significant genes identified in FHS, 185 genes had suitable cis-eQTLs for the MR analysis. We conducted bi-directional MR to test causal relations between expression levels of the 185 genes and circulating IgE levels. We identified four genes-CLC, CCDC21, S100A13, and GCNT1 - as putatively causal for IgE at $\mathrm{P}_{\mathrm{mRNA}_{\rightarrow} \operatorname{IgE}}<0.05$ using the top cis-eQTL for each gene as an instrument variable (Table 3).

Additionally, we performed reverse MR using the top six SNPs from IgE GWAS combined as a polygenic risk score to test if $\mathrm{IgE}$ level affected gene expression levels. None of the four genes from forward MR were significant in reverse $\mathrm{MR}\left(\mathrm{P}_{\mathrm{IgE}} \rightarrow \mathrm{mRNA} \geq 0.05\right)$ (Table 3), suggesting a stronger likelihood that gene expression drives changes in $\mathrm{IgE}$ levels rather than $\mathrm{IgE}$ levels driving gene expression.

\section{Mendelian Randomization for IgE-related diseases: asthma and allergic diseases}

We conducted two-sample MR tests to infer a causal relation between IgE-related gene expression and IgE-related diseases, specifically asthma and allergic diseases. We identified 70 genes that were putatively causal for asthma and 71 genes that were putatively causal for allergic diseases at a Bonferronicorrected $p$-value threshold of $p<2.70 \times 10^{-4}(0.05 / 185)$ (Table 4 , Supplementary Table 8$)$. In comparing the MR results of asthma to those of allergic diseases, the vast majority of putatively causal genes (68) overlapped, which is to be expected given that asthma and allergic diseases are IgE-related (Table 4).

GCNT1, a putatively causal gene for IgE concentration as implicated in our MR analysis of gene expression in relation to IgE levels (beta $=1.503, \mathrm{p}=1.32 \times 10^{-2}$; Table 3 ), is also one of the top results in the MR analysis of expression in relation to asthma and allergic diseases (beta $=58.12, \mathrm{p}<1 \times 10^{-400}$ and beta $=58.88, \mathrm{p}<1 \times 10^{-400}$, respectively; Table 4, Supplementary Table 8).

\section{Discussion}

A thorough understanding of the molecular mechanisms underlying the regulation of $\operatorname{IgE}$ is essential for developing new therapies for asthma and other IgE-mediated diseases, such as allergic rhinitis, atopic dermatitis, and food allergies. To the best of our knowledge, this is the first large-scale TWAS study of total IgE levels that uses MR to infer causal relations between gene expression and IgE levels. In this study, we identified a transcriptomic signature of IgE consisting of 216 FDR-significant genes from discovery in FHS. Gene ontology analysis of this gene set shows that many of these IgE-related genes are enriched in key pathways related to regulation of immune system processes, defense response, and inflammatory response.

MR analysis revealed four genes $(C L C, C C D C 21, S 100 A 13$, and $G C N T 1)$ as nominally significant $\left(\mathrm{P}_{\mathrm{mRNA}_{\rightarrow} \mathrm{IgE}}<0.05\right)$ causal regulators of IgE concentration, suggesting that individual gene transcripts that are associated with IgE concentration likely contribute causally to IgE regulation. Among these is $C L C$ 
(Charcot-Leydon crystal galectin), which is overexpressed in eosinophils that are stimulated following binding of $\mathrm{IgE}^{24}$. Prior studies have identified increased CLC protein levels in induced sputum as a surrogate biomarker of eosinophilic airway inflammation in asthma ${ }^{25}$. Another recent study used a humanized mouse model of asthma to demonstrate that administration of CLC protein with house dust mites (HDM) increased human IgE synthesis compared to when HDMs were administered alone. After developing antibodies that specifically bind and dissolve CLC crystals, it was found that antibiotic treatment completely neutralized the inflammatory effect of CLCs and the ability of CLCs to enhance $\operatorname{IgE}$ synthesis $^{12,26}$. The strong association of the protein encoded by $C L C$ with $\operatorname{IgE}$ concentration, revealed by our TWAS and MR analysis, highlights $C L C$ as a key gene and attractive therapeutic target. While this association does not persist after adjusting for eosinophil count, it is likely because the mechanisms by which CLC SNPs and CLC expression influence IgE concentration-and presumably asthma and allergic diseases - are mediated by eosinophils; thus, adjusting for eosinophils would be expected to mask these associations and may be an overadjustment.

An emerging area of interest in immunology in recent years is the effects on immunity and disease susceptibility of glycosylation of lipid or protein molecules by glycans such as GCNT1 (glucosaminyl (Nacetyl) transferase 1$)^{27}$. GCNT1 is a glycosyltransferase involved in pathways related to metabolism of proteins, and it has several functions involved in immune response. One recent study demonstrated that the protein product of $G C N T 1$, core $2 \beta 1,6-N$-acetylglucosaminyltransferase-I (C2GlcNAcT-I), is necessary not only for the synthesis of P-selectin ligands in neutrophils and T helper 1 (Th1) cells but also for the homing of Th1 cells into sites of inflammation ${ }^{28}$. Additional roles of GCNT1 include partially controlling lymphocyte trafficking into lymph nodes and regulating B cell differentiation via formation and extension of core $2 \mathrm{O}$-glycans ${ }^{29,30}$. These functions are critical to understanding the relations of GCNT1 to IgE concentration given that B cells produce IgE.

Interestingly, a recent knockout study found that GCNT1 deficient mice have neutrophilia and increased susceptibility to tuberculosis infection. The increased susceptibility of GCNT1 deficient mice to infection was largely driven by exacerbated neutrophil counts, which led to lung lesions, inflammation, and other pathologic features in the lungs of affected mice ${ }^{31}$. This link between GCNT1 and neutrophilia is relevant to studying the regulation of $\mathrm{IgE}$ as other studies have shown elevated serum IgE levels to be associated with neutrophilic asthma ${ }^{32}$. Therefore, it is possible that a deficiency, or more broadly an alteration, in GCNTI levels may be linked with elevated IgE levels; additional functional studies are warranted to explore the relationship between $G C N T 1$ and serum IgE concentration. Given that there is no previously published causal association between GCNTI and IgE concentration and that GCNTI appears to play a role in immune processes such as inflammatory Th1 homing, lymphocyte trafficking, and B cell differentiation, GCNTI represents a highly promising therapeutic target for the treatment and prevention of asthma and IgE-related diseases.

Two other nominally significant genes implicated in MR testing - CCDC21 and S100A13 - have no known mechanistic association with serum IgE concentration. CCDC21 encodes a protein (centrosomal protein 85 ) that belongs to the centrosome-associated family of proteins. $S 100 \mathrm{~A} 13$ is a calcium binding gene that encodes for a protein (S100 calcium binding protein A13) belonging to the S100 family of proteins that are involved in a broad range of intracellular and extracellular functions. Extracellular S100 proteins often play crucial roles in regulating immune homeostasis and inflammation ${ }^{33}$. By interacting with cell surface receptors such as RAGE (receptor for advanced glycation end products) in response to cell stress or inflammation, S100 proteins can activate intracellular signaling pathways that induce production of pro-inflammatory cytokines and lead to the migration of neutrophils, monocytes, and macrophages ${ }^{33}$. Various extracellular S100 proteins have been associated with the pathogenesis of inflammatory diseases such as allergy. For example, multiple anti-allergic drugs such as amlexanox, cromolyn, and tranilast have been shown to bind S100A13 and block downstream RAGE signaling ${ }^{33}$. 
medRxiv preprint doi: https://doi.org/10.1101/2020.08.17.20176479; this version posted August 18, 2020. The copyright holder for this preprint (which was not certified by peer review) is the author/funder, who has granted medRxiv a license to display the preprint in perpetuity. All rights reserved. No reuse allowed without permission.

While $C C D C 21$ and S100A13 have not previously been shown to have roles in IgE regulation, our MR tests implicate them as potentially novel biomarkers or therapeutic targets.

In MR analyses of IgE-related diseases, we identified an IgE-associated gene expression signature that is "putatively" causal for asthma. Similar MR results for allergic diseases serve as further confirmation of our MR results of asthma. The identification of GCNT1 as a causal gene for IgE concentration, asthma, and allergic diseases provides additional support for our hypothesis that IgE-associated gene expression changes impact IgE regulation and play a role in multiple IgE-related diseases. Based on our finding of a putatively causal role of GCNTI in IgE regulation and in asthma and allergic diseases, we hypothesize that GCNTI and the other IgE-associated genes identified in this study are related to the pathobiology of IgE-related diseases, including asthma and allergic diseases, and that they represent compelling therapeutic targets for treatment and prevention of these disorders.

There are several limitations to our study. First, gene expression was measured in whole blood, which may not be representative of tissue-specific effects. Second, the serum IgE concentration and gene expression measurements were obtained approximately six years apart in FHS participants. This time difference may bias our results toward the null. Third, there are significant differences in the age and IgE concentration of the FHS participants compared to those of GACRS/CAMP. The average age of the FHS study participants was 55 years, which was significantly higher than the average age of GACRS (9 years) and CAMP (20 years) participants. There was no significant difference in serum IgE concentration between the GACRS and CAMP cohorts, despite the ten-year age difference; however, the IgE levels of the GACRS and CAMP cohorts were considerably higher than those of FHS ( $\log _{10} \operatorname{IgE}$ levels 2.5 and 2.5 vs. 1.52). This is likely due to the fact that all the participants in GACRS and CAMP had asthma, which is associated with elevated $\mathrm{IgE}$ concentration.

Of the 216 IgE-associated transcripts $(F D R<0.05)$ in FHS discovery, 59 genes bi-directionally replicated between the FHS and the GACRS/CAMP. This high-degree of replication is notable given the previously described differences in cohort study populations.

We performed a TWAS of $\operatorname{IgE}$ and then probed the directional relations between $\operatorname{IgE}$ and gene expression, which identified four genes as causally associated with $\operatorname{IgE}$ levels. $C L C$ is a well-documented gene with known associations with eosinophils and IgE; CCDC21 and S100A13 do not yet have wellunderstood associations with IgE and represent novel findings. Given its myriad of roles in the regulation of the immune response, GCNT1 is a particularly attractive potential drug target given that in addition to its putatively causal relation to IgE levels it also was causal for asthma and allergic diseases. Our findings build upon prior knowledge of $\mathrm{IgE}$ regulation and provide a deeper understanding of the underlying molecular mechanisms. The IgE-associated genes that we identified-particularly those implicated in MR testing — can be explored as promising therapeutic targets for asthma and IgE-related diseases. 
medRxiv preprint doi: https://doi.org/10.1101/2020.08.17.20176479; this version posted August 18, 2020. The copyright holder for this preprint (which was not certified by peer review) is the author/funder, who has granted medRxiv a license to display the preprint in perpetuity.

All rights reserved. No reuse allowed without permission.

\section{Acknowledgments}

The Framingham Heart Study is funded by National Institutes of Health contract N01-HC-25195 and HHSN268201500001I. The work in this project was funded by the Division of Intramural Research, National Heart, Lung, and Blood Institute, National Institutes of Health, Bethesda, MD (D. Levy, Principal Investigator).

Disclaimer: The views expressed in this manuscript are those of the authors and do not necessarily represent the views of the National Heart, Lung, and Blood Institute; the National Institutes of Health; or the U.S. Department of Health and Human Services. 
medRxiv preprint doi: https://doi.org/10.1101/2020.08.17.20176479; this version posted August 18, 2020. The copyright holder for this preprint (which was not certified by peer review) is the author/funder, who has granted medRxiv a license to display the preprint in perpetuity. All rights reserved. No reuse allowed without permission.

\section{References}

1. Oettgen, H.C. Fifty years later: Emerging functions of IgE antibodies in host defense, immune regulation, and allergic diseases. The Journal of allergy and clinical immunology 137, 1631-1645 (2016).

2. Kelly, B.T. \& Grayson, M.H. Immunoglobulin E, what is it good for? Annals of allergy, asthma \& immunology : official publication of the American College of Allergy, Asthma, \& Immunology 116, 183-187 (2016).

3. Mukai, K., Tsai, M., Starkl, P., Marichal, T. \& Galli, S.J. IgE and mast cells in host defense against parasites and venoms. Seminars in Immunopathology 38, 581-603 (2016).

4. Hu, J. et al. Anti-IgE therapy for IgE-mediated allergic diseases: from neutralizing IgE antibodies to eliminating $\operatorname{IgE}(+)$ B cells. Clinical and translational allergy 8, 27-27 (2018).

5. Levin, A.M. et al. A meta-analysis of genome-wide association studies for serum total IgE in diverse study populations. The Journal of allergy and clinical immunology 131, 1176-1184 (2013).

6. Yatagai, Y. et al. Genome-wide association study for levels of total serum IgE identifies HLA-C in a Japanese population. PloS one 8, e80941-e80941 (2013).

7. Moffatt, M.F. et al. A large-scale, consortium-based genomewide association study of asthma. The New England journal of medicine 363, 1211-1221 (2010).

8. Granada, M. et al. A genome-wide association study of plasma total IgE concentrations in the Framingham Heart Study. The Journal of allergy and clinical immunology 129, 840-845.e21 (2012).

9. Liang, L. et al. An epigenome-wide association study of total serum immunoglobulin E concentration. Nature 520, 670-674 (2015).

10. Weidinger, S. et al. Genome-wide scan on total serum IgE levels identifies FCER1A as novel susceptibility locus. PLoS genetics 4, e1000166-e1000166 (2008).

11. Everson, T.M. et al. DNA methylation loci associated with atopy and high serum IgE: a genomewide application of recursive Random Forest feature selection. Genome medicine 7, 89-89 (2015).

12. Virkud, Y.V. et al. Novel eosinophilic gene expression networks associated with IgE in two distinct asthma populations. Clin Exp Allergy 48, 1654-1664 (2018).

13. Zhu, Z. et al. A genome-wide cross-trait analysis from UK Biobank highlights the shared genetic architecture of asthma and allergic diseases. Nat Genet 50, 857-864 (2018).

14. Dawber, T.R., Meadors, G.F. \& Moore, F.E., Jr. Epidemiological approaches to heart disease: the Framingham Study. Am J Public Health Nations Health 41, 279-81 (1951).

15. Yunginger, J.W. et al. Quantitative IgE antibody assays in allergic diseases. J Allergy Clin Immunol 105, 1077-84 (2000).

16. Joehanes, R. et al. Integrated genome-wide analysis of expression quantitative trait loci aids interpretation of genomic association studies. Genome biology 18, 16 (2017).

17. Joehanes, R. et al. Integrated genome-wide analysis of expression quantitative trait loci aids interpretation of genomic association studies. Genome Biol 18, 16 (2017).

18. The Childhood Asthma Management Program (CAMP): design, rationale, and methods. Childhood Asthma Management Program Research Group. Control Clin Trials 20, 91-120 (1999).

19. Recruitment of participants in the childhood Asthma Management Program (CAMP). I. Description of methods: Childhood Asthma Management Program Research Group. J Asthma 36, 217-37 (1999).

20. Croteau-Chonka, D.C. et al. Gene Expression Profiling in Blood Provides Reproducible Molecular Insights into Asthma Control. Am J Respir Crit Care Med 195, 179-188 (2017).

21. Kelly, R.S. et al. Metabolomic profiling of lung function in Costa-Rican children with asthma. Biochim Biophys Acta Mol Basis Dis 1863, 1590-1595 (2017). 
medRxiv preprint doi: https://doi.org/10.1101/2020.08.17.20176479; this version posted August 18, 2020. The copyright holder for this preprint

(which was not certified by peer review) is the author/funder, who has granted medRxiv a license to display the preprint in perpetuity.

All rights reserved. No reuse allowed without permission.

22. Bourgon, R., Gentleman, R. \& Huber, W. Independent filtering increases detection power for high-throughput experiments. Proceedings of the National Academy of Sciences of the United States of America 107, 9546-9551 (2010).

23. Rau, A., Marot, G. \& Jaffrezic, F. Differential meta-analysis of RNA-seq data from multiple studies. BMC Bioinformatics 15, 91 (2014).

24. Su, J. A Brief History of Charcot-Leyden Crystal Protein/Galectin-10 Research. Molecules (Basel, Switzerland) 23, 2931 (2018).

25. Nyenhuis, S.M. et al. Charcot-Leyden crystal protein/galectin-10 is a surrogate biomarker of eosinophilic airway inflammation in asthma. Biomark Med 13, 715-724 (2019).

26. Persson, E.K. et al. Protein crystallization promotes type 2 immunity and is reversible by antibody treatment. Science 364(2019).

27. Lyons, J.J., Milner, J.D. \& Rosenzweig, S.D. Glycans Instructing Immunity: The Emerging Role of Altered Glycosylation in Clinical Immunology. Frontiers in pediatrics 3, 54-54 (2015).

28. Mardahl, M. et al. Core 2 ß1,6-N-acetylglucosaminyltransferase-I, crucial for P-selectin ligand expression is controlled by a distal enhancer regulated by STAT4 and T-bet in CD4+ T helper cells 1. Mol Immunol 77, 132-40 (2016).

29. Veerman, K., Tardiveau, C., Martins, F., Coudert, J. \& Girard, J.P. Single-Cell Analysis Reveals Heterogeneity of High Endothelial Venules and Different Regulation of Genes Controlling Lymphocyte Entry to Lymph Nodes. Cell Rep 26, 3116-3131.e5 (2019).

30. Giovannone, N. et al. Human B Cell Differentiation Is Characterized by Progressive Remodeling of O-Linked Glycans. Frontiers in immunology 9, 2857-2857 (2018).

31. Fonseca, K.L. et al. Deficiency in the glycosyltransferase Gent1 increases susceptibility to tuberculosis through a mechanism involving neutrophils. Mucosal Immunology (2020).

32. Bullone, M. et al. Elevated serum IgE, oral corticosteroid dependence and IL-17/22 expression in highly neutrophilic asthma. European Respiratory Journal 54, 1900068 (2019).

33. Xia, C., Braunstein, Z., Toomey, A.C., Zhong, J. \& Rao, X. S100 Proteins As an Important Regulator of Macrophage Inflammation. Front Immunol 8, 1908 (2017). 
Table 1. Top thirty genes associated with total IgE levels in the FHS.

\begin{tabular}{|cccccc|}
\hline Gene Symbol & Chr & Beta & SE & P-Value & FDR Value \\
\hline IL5RA & 3 & 0.144 & 0.011 & $1.88 \mathrm{E}-40$ & $3.37 \mathrm{E}-36$ \\
\hline SLC29A1 & 6 & 0.085 & 0.007 & $3.23 \mathrm{E}-34$ & $2.88 \mathrm{E}-30$ \\
\hline CLC & 19 & 0.172 & 0.014 & $3.60 \mathrm{E}-32$ & $2.15 \mathrm{E}-28$ \\
\hline IL1RL1 & 2 & 0.131 & 0.011 & $6.41 \mathrm{E}-31$ & $2.87 \mathrm{E}-27$ \\
\hline EMR1 & 19 & 0.111 & 0.010 & $1.13 \mathrm{E}-28$ & $4.04 \mathrm{E}-25$ \\
\hline HRH4 & 18 & 0.118 & 0.011 & $8.13 \mathrm{E}-26$ & $2.42 \mathrm{E}-22$ \\
\hline DACH1 & 13 & 0.050 & 0.005 & $4.26 \mathrm{E}-25$ & $1.09 \mathrm{E}-21$ \\
\hline CCR4 & 3 & 0.084 & 0.008 & $1.04 \mathrm{E}-23$ & $2.32 \mathrm{E}-20$ \\
\hline TEC & 4 & 0.067 & 0.007 & $1.31 \mathrm{E}-22$ & $2.46 \mathrm{E}-19$ \\
\hline SYNE1 & 6 & 0.068 & 0.007 & $1.38 \mathrm{E}-22$ & $2.46 \mathrm{E}-19$ \\
\hline ADORA3 & 1 & 0.061 & 0.006 & $1.32 \mathrm{E}-21$ & $2.15 \mathrm{E}-18$ \\
\hline ALOX15 & 17 & 0.093 & 0.010 & $7.64 \mathrm{E}-21$ & $1.14 \mathrm{E}-17$ \\
\hline CYSLTR2 & 13 & 0.089 & 0.010 & $4.43 \mathrm{E}-20$ & $6.10 \mathrm{E}-17$ \\
\hline SMPD3 & 16 & 0.039 & 0.004 & $5.92 \mathrm{E}-20$ & $7.55 \mathrm{E}-17$ \\
\hline IKZF2 & 2 & 0.058 & 0.007 & $3.18 \mathrm{E}-18$ & $3.79 \mathrm{E}-15$ \\
\hline PRSS33 & 16 & 0.028 & 0.003 & $5.30 \mathrm{E}-18$ & $5.92 \mathrm{E}-15$ \\
\hline PDE4D & 5 & 0.037 & 0.004 & $7.99 \mathrm{E}-18$ & $8.40 \mathrm{E}-15$ \\
\hline CAT & 11 & 0.066 & 0.008 & $4.86 \mathrm{E}-17$ & $4.82 \mathrm{E}-14$ \\
\hline SIGLEC8 & 19 & 0.042 & 0.005 & $1.52 \mathrm{E}-15$ & $1.43 \mathrm{E}-12$ \\
\hline IDO1 & 8 & 0.070 & 0.009 & $3.20 \mathrm{E}-15$ & $2.86 \mathrm{E}-12$ \\
\hline C20rf46 & 2 & 0.058 & 0.007 & $8.65 \mathrm{E}-15$ & $7.37 \mathrm{E}-12$ \\
\hline VSTM1 & 19 & 0.087 & 0.011 & $5.22 \mathrm{E}-14$ & $4.24 \mathrm{E}-11$ \\
\hline CD200R1 & 3 & 0.047 & 0.006 & $4.84 \mathrm{E}-13$ & $3.76 \mathrm{E}-10$ \\
\hline ARHGAP10 & 4 & 0.033 & 0.005 & $7.98 \mathrm{E}-13$ & $5.94 \mathrm{E}-10$ \\
\hline CCR3 & 3 & 0.070 & 0.010 & $2.38 \mathrm{E}-12$ & $1.67 \mathrm{E}-09$ \\
\hline CEBPE & 14 & 0.048 & 0.007 & $2.43 \mathrm{E}-12$ & $1.67 \mathrm{E}-09$ \\
\hline GPR114 & 16 & 0.023 & 0.003 & $5.64 \mathrm{E}-12$ & $3.73 \mathrm{E}-09$ \\
\hline ANXA1 & 9 & 0.043 & 0.006 & $7.19 \mathrm{E}-12$ & $4.59 \mathrm{E}-09$ \\
\hline C15orf43 & 15 & 0.037 & 0.005 & $8.92 \mathrm{E}-12$ & $5.50 \mathrm{E}-09$ \\
\hline CAMK1 & 3 & 0.024 & 0.004 & $1.50 \mathrm{E}-11$ & $8.95 \mathrm{E}-09$ \\
\hline & & & & \\
\hline & 3 & & & \\
\hline & & & & \\
\hline
\end{tabular}

Table 2. Gene ontology defned biological processes associated with total IgE levels in the FDRsignificant transcripts in the FHS cohort $(n=216)$.

\begin{tabular}{lccc} 
GO biological process & \# Genes in GO group & P-Value & FDR Value \\
\hline Regulation of Immune System Process & 40 & $6.69 \mathrm{E}-15$ & $1.98 \mathrm{E}-11$ \\
\hline Defense Response & 41 & $8.10 \mathrm{E}-15$ & $1.98 \mathrm{E}-11$ \\
\hline Inflammatory Response & 27 & $3.58 \mathrm{E}-14$ & $5.82 \mathrm{E}-11$ \\
\hline Leukocyte Migration & 21 & $1.21 \mathrm{E}-12$ & $1.47 \mathrm{E}-09$ \\
Neurogenesis & 35 & $8.15 \mathrm{E}-12$ & $7.96 \mathrm{E}-09$ \\
\hline Immune System Development & 27 & $1.42 \mathrm{E}-11$ & $1.26 \mathrm{E}-08$ \\
\hline Leukocyte Proliferation & 14 & $2.0 \mathrm{E}-09$ & $6.98 \mathrm{E}-07$ \\
Cytokine Mediated Signaling Pathway & 21 & $4.84 \mathrm{E}-09$ & $1.57 \mathrm{E}-06$ \\
Response to Cytokine & 26 & $5.35 \mathrm{E}-09$ & $1.67 \mathrm{E}-06$
\end{tabular}




\begin{tabular}{lccc} 
Reactome Signaling by Interleukins & 16 & $9.39 \mathrm{E}-09$ & $2.58 \mathrm{E}-06$ \\
Cytokine Production & 20 & $3.62 \mathrm{E}-08$ & $7.62 \mathrm{E}-06$ \\
\hline Lymphocyte Activation & 19 & $4.2 \mathrm{E}-08$ & $8.54 \mathrm{E}-06$ \\
Neuron Differentiation & 26 & $5.97 \mathrm{E}-08$ & $1.17 \mathrm{E}-05$ \\
\hline Positive Regulation of Hemopoiesis & 10 & $1.23 \mathrm{E}-07$ & $2.03 \mathrm{E}-05$ \\
\hline Interleukin 5 Production & 5 & $1.28 \mathrm{E}-07$ & $2.08 \mathrm{E}-05$ \\
Myeloid Cell Homeostasis & 9 & $1.61 \mathrm{E}-07$ & $2.54 \mathrm{E}-05$ \\
\hline Leukocyte Cell Cell Adhesion & 12 & $6.28 \mathrm{E}-07$ & $7.96 \mathrm{E}-05$ \\
Immune Effector Process & 23 & $8.35 \mathrm{E}-07$ & $9.93 \mathrm{E}-05$ \\
Myeloid Cell Differentiation & 13 & $8.44 \mathrm{E}-07$ & $9.93 \mathrm{E}-05$ \\
Neuron Development & 21 & $1.43 \mathrm{E}-06$ & $1.57 \mathrm{E}-04$ \\
Granulocyte Migration & 8 & $1.49 \mathrm{E}-06$ & $1.62 \mathrm{E}-04$ \\
\hline Leukocyte Differentiation & 14 & $1.65 \mathrm{E}-06$ & $1.77 \mathrm{E}-04$ \\
\hline
\end{tabular}

Table 3. Bi-directional MR results for genes putatively causal for $\operatorname{IgE}$ levels at $p<0.05(n=4)$.

\begin{tabular}{|c|c|c|c|c|c|c|c|c|}
\hline $\begin{array}{c}\text { Gene } \\
\text { Symbol }\end{array}$ & SNP & Chr & $\begin{array}{c}\text { Beta } \\
\left(\mathrm{mRNA}_{\rightarrow} \text { IgE }\right)\end{array}$ & $\begin{array}{c}\mathbf{S E} \\
\left(\mathrm{mRNA}_{\rightarrow} \mathbf{I g E}\right)\end{array}$ & $\begin{array}{l}\text { P-Value } \\
(\text { mRNA } \rightarrow \text { IgE) }\end{array}$ & $\begin{array}{c}\text { Beta } \\
\left(\operatorname{IgE}_{\rightarrow} \text { mRNA }\right)\end{array}$ & $\begin{array}{c}\text { SE } \\
\left(\operatorname{IgE}_{\rightarrow} \text { mRNA }\right)\end{array}$ & $\begin{array}{l}\text { P-Value } \\
\left(\mathrm{IgE}_{\rightarrow} \text { mRNA }\right)\end{array}$ \\
\hline CCDC21 & rs869683 & 1 & 0.571 & 0.197 & $3.67 \mathrm{E}-03$ & -0.005 & 0.024 & $8.46 \mathrm{E}-01$ \\
\hline S100A13 & rs9661993 & 1 & -0.166 & 0.062 & 7.35E-03 & -0.097 & 0.057 & $9.15 \mathrm{E}-02$ \\
\hline GCNT1 & rs11144929 & 9 & 1.503 & 0.606 & $1.32 \mathrm{E}-02$ & -0.018 & 0.03 & $5.62 \mathrm{E}-01$ \\
\hline CLC & rs17709471 & 19 & 0.467 & 0.198 & $1.80 \mathrm{E}-02$ & -0.061 & 0.082 & $4.58 \mathrm{E}-01$ \\
\hline
\end{tabular}

Table 4. MR results for genes putatively causal for asthma at Bonferroni-corrected $\mathrm{p}<2.70 \times 10^{-4}(\mathrm{n}=70)$.

\begin{tabular}{|ccccccc|}
\hline Gene Symbol & Transcript \# & Method & nsnp & Beta & SE & P-Value \\
\hline GPI & 3829687 & Wald ratio & 1 & 23.67 & 0.62 & $0.00 \mathrm{E}+00$ \\
\hline PGD & 2319802 & Wald ratio & 1 & 70.20 & 1.08 & $0.00 \mathrm{E}+00$ \\
\hline NDFIP2 & 3495076 & Wald ratio & 1 & 76.43 & 1.01 & $0.00 \mathrm{E}+00$ \\
\hline CYSLTR2 & 3489138 & Wald ratio & 1 & 21.71 & 0.30 & $0.00 \mathrm{E}+00$ \\
\hline GPR114 & 3662774 & Wald ratio & 1 & -60.23 & 0.94 & $0.00 \mathrm{E}+00$ \\
\hline CPT1A & 3379644 & Wald ratio & 1 & 34.88 & 0.66 & $0.00 \mathrm{E}+00$ \\
\hline ZNF610 & 3840164 & Wald ratio & 1 & -51.06 & 0.72 & $0.00 \mathrm{E}+00$ \\
\hline ABTB2 & 3368940 & Wald ratio & 1 & 48.78 & 0.67 & $0.00 \mathrm{E}+00$ \\
\hline CD9 & 3402315 & Wald ratio & 1 & 26.12 & 0.55 & $0.00 \mathrm{E}+00$ \\
\hline STK17A & 2999485 & Wald ratio & 1 & 42.04 & 0.71 & $0.00 \mathrm{E}+00$ \\
\hline SMPD3 & 3696317 & Wald ratio & 1 & -59.35 & 1.01 & $0.00 \mathrm{E}+00$ \\
\hline GCNT1 & 3175494 & Wald ratio & 1 & 58.12 & 0.84 & $0.00 \mathrm{E}+00$ \\
\hline CCR4 & 2616131 & Wald ratio & 1 & 20.37 & 0.32 & $0.00 \mathrm{E}+00$ \\
\hline PRF1 & 3293435 & Wald ratio & 1 & 40.38 & 0.93 & $0.00 \mathrm{E}+00$ \\
\hline ATP8B2 & 2360206 & Wald ratio & 1 & 47.85 & 0.71 & $0.00 \mathrm{E}+00$ \\
\hline ZMYND11 & 3231389 & Wald ratio & 1 & -71.58 & 1.00 & $0.00 \mathrm{E}+00$ \\
\hline OLIG1 & 3918429 & Wald ratio & 1 & 96.66 & 1.41 & $0.00 \mathrm{E}+00$ \\
\hline FBP1 & 3215570 & Wald ratio & 1 & -62.42 & 1.16 & $0.00 \mathrm{E}+00$ \\
\hline ORM2 & 3186137 & Wald ratio & 1 & -29.95 & 0.38 & $0.00 \mathrm{E}+00$ \\
\hline SAMSN1 & 3925473 & Wald ratio & 1 & 51.39 & 0.82 & $0.00 \mathrm{E}+00$ \\
\hline FCRL2 & 2439052 & Wald ratio & 1 & -52.09 & 0.83 & $0.00 \mathrm{E}+00$ \\
\hline
\end{tabular}




\begin{tabular}{|c|c|c|c|c|c|c|}
\hline CCDC86 & 3332548 & Wald ratio & 1 & 58.53 & 0.80 & $0.00 \mathrm{E}+00$ \\
\hline KIT & 2727587 & Wald ratio & 1 & 86.75 & 1.15 & $0.00 \mathrm{E}+00$ \\
\hline PLD3 & 3833443 & Wald ratio & 1 & 40.25 & 0.87 & $0.00 \mathrm{E}+00$ \\
\hline BHLHE40 & 2608725 & Wald ratio & 1 & -24.02 & 0.47 & $0.00 \mathrm{E}+00$ \\
\hline THUMPD1 & 3683783 & Wald ratio & 1 & 31.31 & 0.42 & $0.00 \mathrm{E}+00$ \\
\hline CLINT1 & 2883609 & Wald ratio & 1 & 59.72 & 0.82 & $0.00 \mathrm{E}+00$ \\
\hline IL5RA & 2660617 & Wald ratio & 1 & 44.95 & 0.62 & $0.00 \mathrm{E}+00$ \\
\hline IL2RA & 3275729 & Wald ratio & 1 & 28.73 & 0.40 & $0.00 \mathrm{E}+00$ \\
\hline SRGAP3 & 2662087 & Wald ratio & 1 & 79.94 & 1.07 & $0.00 \mathrm{E}+00$ \\
\hline NUPL1 & 3482219 & Wald ratio & 1 & 53.59 & 1.27 & $0.00 \mathrm{E}+00$ \\
\hline NUP93 & 3662265 & Wald ratio & 1 & 53.06 & 0.66 & $0.00 \mathrm{E}+00$ \\
\hline IL17RB & 2624565 & Wald ratio & 1 & -33.81 & 0.45 & $0.00 \mathrm{E}+00$ \\
\hline CRIP1 & 3554851 & Wald ratio & 1 & 28.22 & 0.43 & $0.00 \mathrm{E}+00$ \\
\hline GPR137B & 2386747 & Wald ratio & 1 & -65.16 & 0.85 & $0.00 \mathrm{E}+00$ \\
\hline ID2 & 2468622 & Wald ratio & 1 & -38.70 & 0.49 & $0.00 \mathrm{E}+00$ \\
\hline CLCNKB & 2322264 & Wald ratio & 1 & 68.19 & 0.93 & $0.00 \mathrm{E}+00$ \\
\hline PLAC4 & 3932917 & Wald ratio & 1 & -15.40 & 0.21 & $0.00 \mathrm{E}+00$ \\
\hline SYNE1 & 2979871 & Wald ratio & 1 & -45.92 & 1.08 & $0.00 \mathrm{E}+00$ \\
\hline FCRLA & 2363852 & Wald ratio & 1 & -66.59 & 0.70 & $0.00 \mathrm{E}+00$ \\
\hline COBLL1 & 2584787 & Wald ratio & 1 & 84.94 & 1.28 & $0.00 \mathrm{E}+00$ \\
\hline INPP5A & 3272205 & Wald ratio & 1 & -22.45 & 0.50 & $0.00 \mathrm{E}+00$ \\
\hline SEMA7A & 3632907 & Wald ratio & 1 & -49.69 & 1.14 & $0.00 \mathrm{E}+00$ \\
\hline ADORA3 & 2427981 & Inverse variance weighted & 2 & 19.38 & 0.43 & $0.00 \mathrm{E}+00$ \\
\hline GATA3 & 3234277 & Wald ratio & 1 & 42.41 & 0.58 & $0.00 \mathrm{E}+00$ \\
\hline PMP22 & 3746574 & Inverse variance weighted & 2 & 30.48 & 0.82 & $5.27 \mathrm{E}-303$ \\
\hline P4HA1 & 3294159 & Wald ratio & 1 & 10.88 & 0.30 & $1.23 \mathrm{E}-288$ \\
\hline KLHL6 & 2708066 & Wald ratio & 1 & -21.75 & 0.65 & $5.52 \mathrm{E}-244$ \\
\hline PPM1L & 2650393 & Wald ratio & 1 & -11.22 & 0.35 & $5.00 \mathrm{E}-224$ \\
\hline GRB10 & 3050462 & Wald ratio & 1 & 28.66 & 0.94 & $5.03 \mathrm{E}-204$ \\
\hline CDK15 & 2522916 & Wald ratio & 1 & 10.88 & 0.39 & $5.54 \mathrm{E}-175$ \\
\hline BRI3BP & 3436544 & Wald ratio & 1 & 31.48 & 1.14 & $5.51 \mathrm{E}-169$ \\
\hline SEMA5A & 2847967 & Wald ratio & 1 & 36.84 & 1.44 & $3.84 \mathrm{E}-145$ \\
\hline HRASLS2 & 3376512 & Wald ratio & 1 & 10.69 & 0.43 & $7.30 \mathrm{E}-139$ \\
\hline PDE8A & 3606034 & Wald ratio & 1 & 23.80 & 1.16 & $2.96 \mathrm{E}-93$ \\
\hline CD63 & 3457160 & Inverse variance weighted & 2 & -80.22 & 5.03 & $3.30 \mathrm{E}-57$ \\
\hline VKORC1L1 & 3005280 & Wald ratio & 1 & 22.91 & 1.44 & $8.49 \mathrm{E}-57$ \\
\hline SLC35D1 & 2417095 & Inverse variance weighted & 3 & 14.53 & 1.87 & $8.13 \mathrm{E}-15$ \\
\hline FMNL3 & 3454006 & Inverse variance weighted & 2 & -37.28 & 5.70 & $6.10 \mathrm{E}-11$ \\
\hline TNIK & 2705266 & Inverse variance weighted & 3 & -64.09 & 9.84 & 7.23E-11 \\
\hline VSTM1 & 3870449 & Inverse variance weighted & 3 & -6.97 & 1.17 & 2.49E-09 \\
\hline CCL23 & 3753985 & Inverse variance weighted & 2 & -36.91 & 7.31 & 4.35E-07 \\
\hline VLDLR & 3160175 & Inverse variance weighted & 5 & 33.87 & 6.73 & 4.76E-07 \\
\hline TNFRSF9 & 2395146 & Inverse variance weighted & 2 & -12.54 & 2.60 & $1.41 \mathrm{E}-06$ \\
\hline ABCC1 & 3649890 & Inverse variance weighted & 2 & -44.86 & 10.32 & $1.39 \mathrm{E}-05$ \\
\hline KLF6 & 3274361 & Inverse variance weighted & 2 & -54.40 & 13.38 & 4.79E-05 \\
\hline CASP3 & 2796484 & Inverse variance weighted & 2 & -11.03 & 2.74 & $5.69 \mathrm{E}-05$ \\
\hline
\end{tabular}


Figure 1. Flowchart of study design.

$\begin{array}{ccc}\text { TEC } & 2768396 & \text { Inve } \\ \text { GZMB } & 3558375 & \text { Inv } \\ \text { INPP1 } & 2520113 & \text { Inv } \\ & & \\ & & \\ & \\ \text { ure 1. Flowchart of study design. }\end{array}$

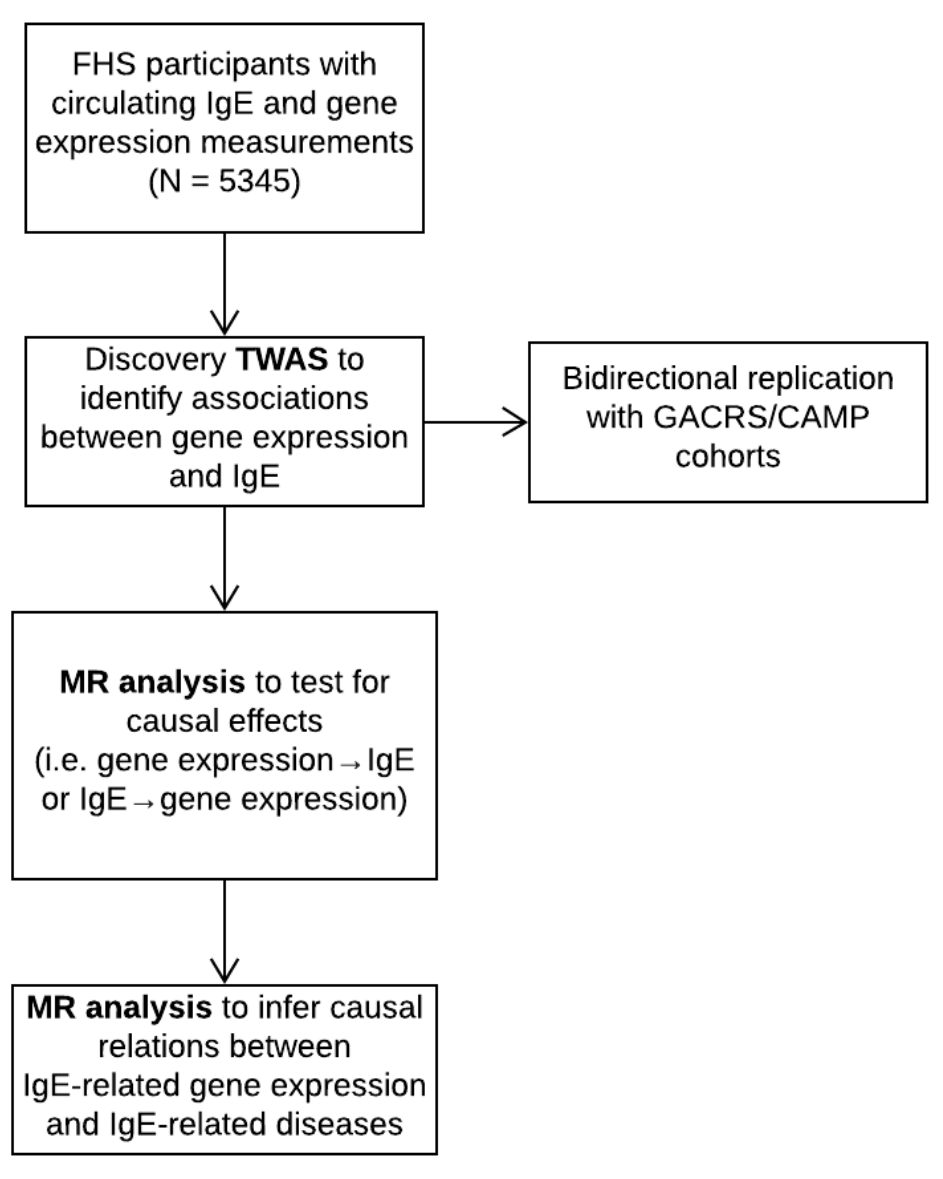


medRxiv preprint doi: https://doi.org/10.1101/2020.08.17.20176479; this version posted August 18, 2020. The copyright holder for this preprint (which was not certified by peer review) is the author/funder, who has granted medRxiv a license to display the preprint in perpetuity. All rights reserved. No reuse allowed without permission.

Figure 2. Manhattan plot of FHS GWAS results. The horizontal line shows the threshold for genomewide significance $\left(\mathrm{P}\right.$-value $\left.<5 \times 10^{-8}\right)$.

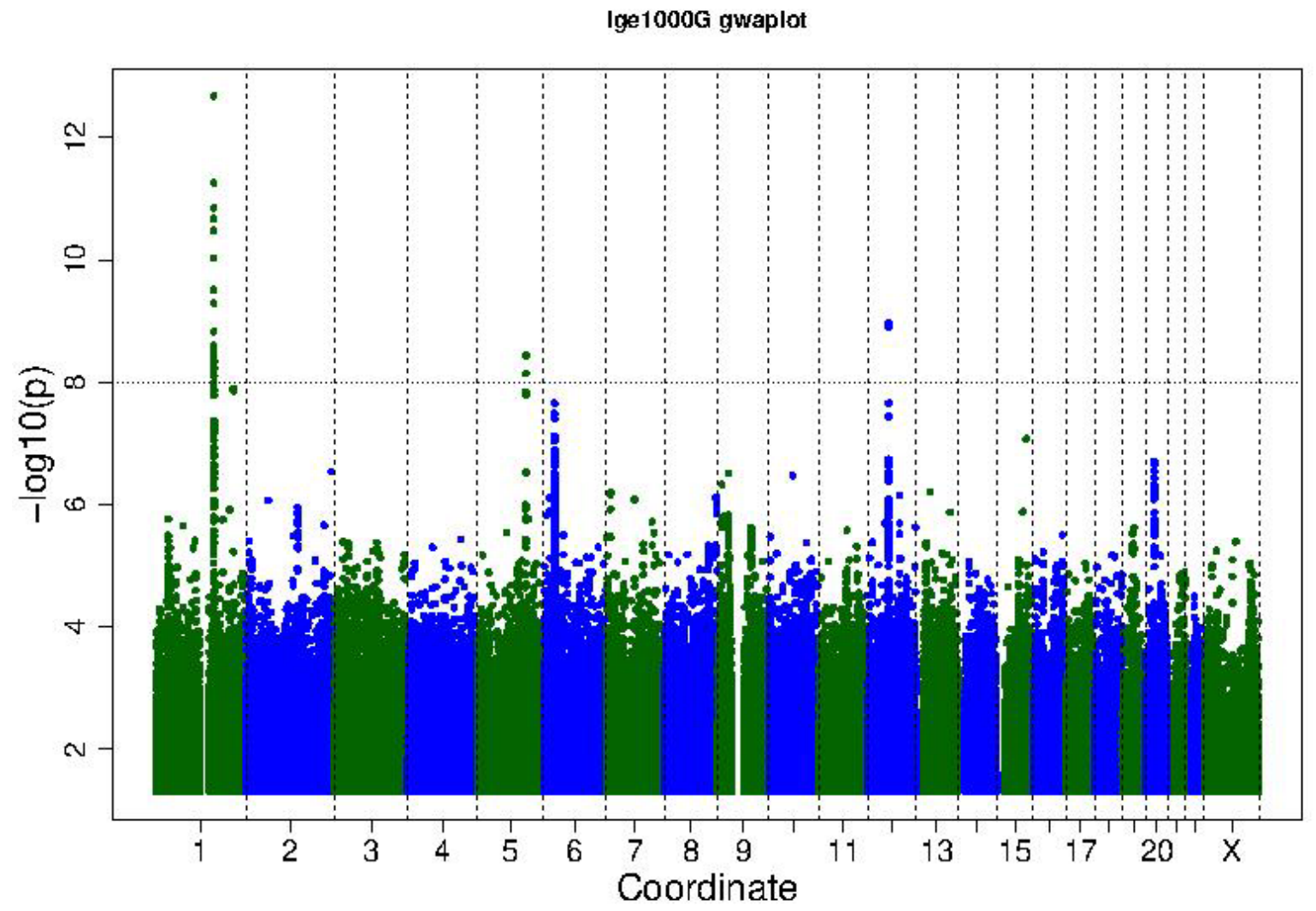


medRxiv preprint doi: https://doi.org/10.1101/2020.08.17.20176479; this version posted August 18, 2020. The copyright holder for this preprint (which was not certified by peer review) is the author/funder, who has granted medRxiv a license to display the preprint in perpetuity. All rights reserved. No reuse allowed without permission.

Figure 3. Q-Q plot of FHS GWAS results. The Q-Q plot shows observed vs. expected -log10(P-values) of the GWAS results. The straight line represents the SNP distribution under the null hypothesis.

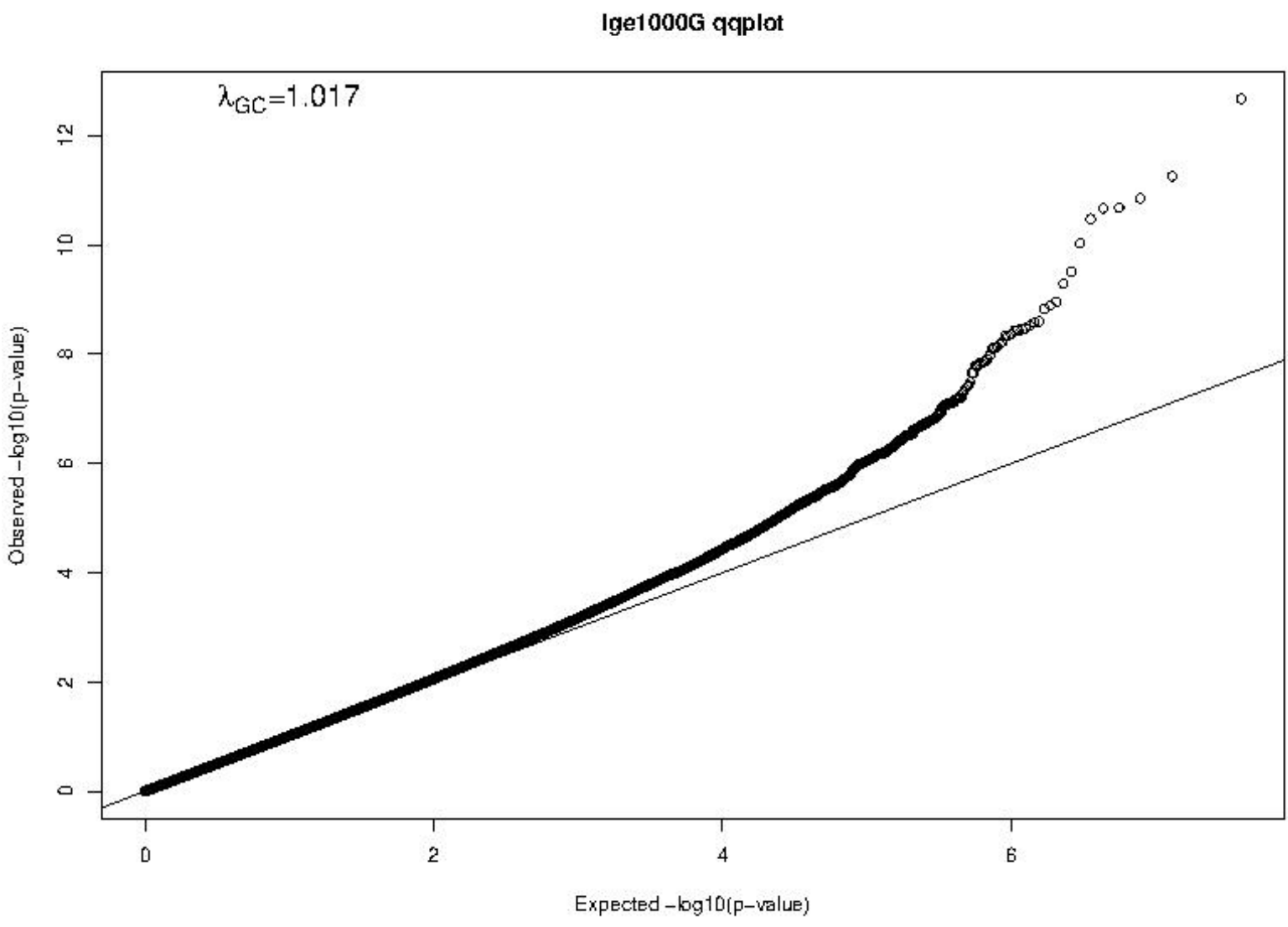


medRxiv preprint doi: https://doi.org/10.1101/2020.08.17.20176479; this version posted August 18, 2020. The copyright holder for this preprint (which was not certified by peer review) is the author/funder, who has granted medRxiv a license to display the preprint in perpetuity.

All rights reserved. No reuse allowed without permission.

Figure 4. Volcano plot of FHS TWAS results. P-value $<0.05$ significance threshold is the lower line and $\mathrm{P}$-value $<6.09 \times 10^{-4}$ (which corresponds to an FDR $<0.05$ ) is the upper line.

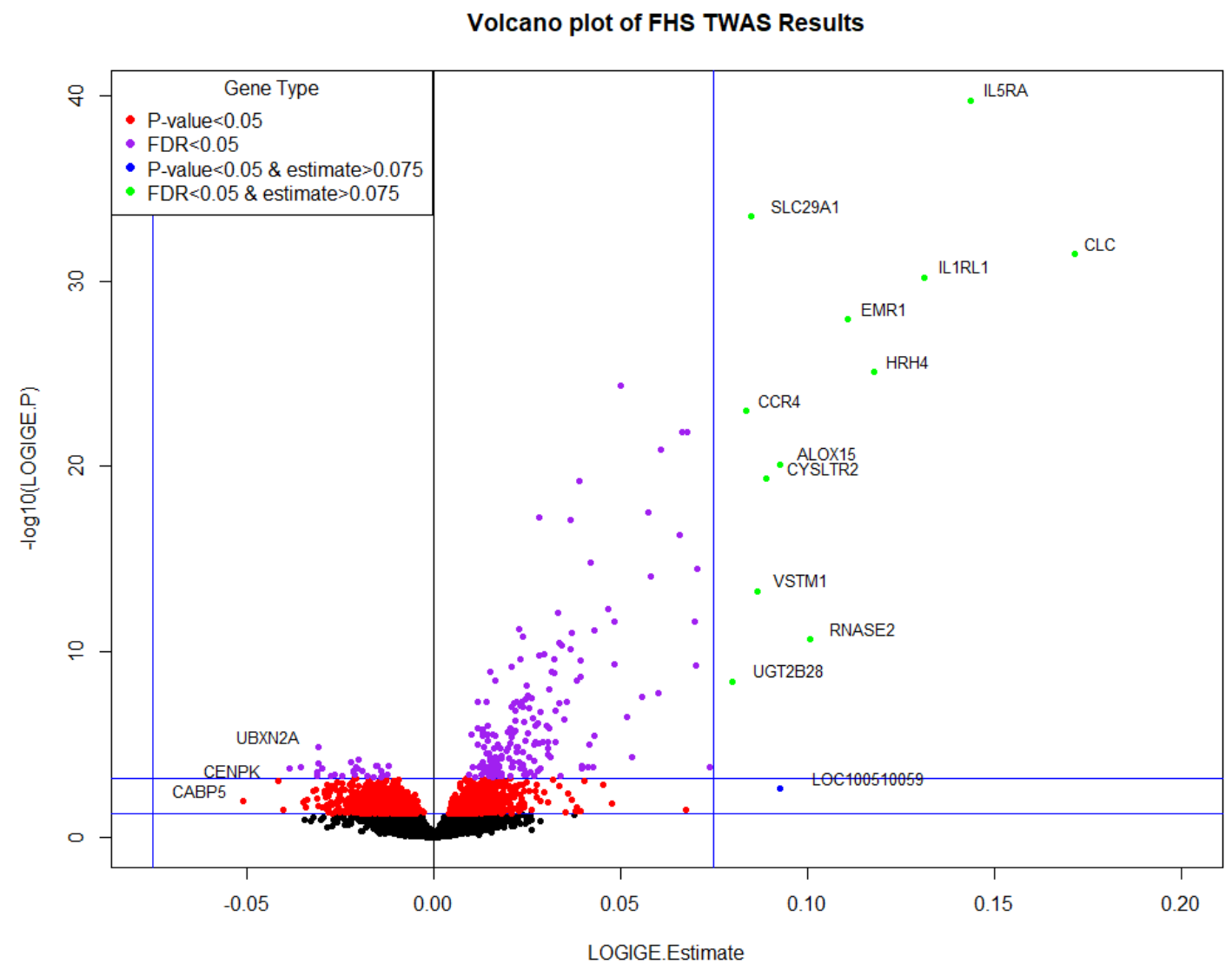

